\title{
Comunicação
}

\section{Milho consorciado com capim tifton na Amazônia sul ocidental ${ }^{1}$}

\author{
Jairo Rafael Machado Dias ${ }^{1 *}$, Tyago Matheus Reinicke ${ }^{2}$, Elvino Ferreira ${ }^{2}$, Larissa Cristina Torrezani Starling ${ }^{2}$, \\ Fábio Régis de Souza ${ }^{2}$, Anderson Cristian Bergamin², Fábio Luiz Partelli ${ }^{3}$
}

$10.1590 / 0034-737 X 201663020020$

\section{RESUMO}

Objetivou-se, com este trabalho, avaliar o desempenho do consórcio de milho com capim tifton na Amazônia sul ocidental. O delineamento experimental utilizado foi em blocos casualizados, com seis tratamentos e quatro repetições. Os tratamentos foram constituídos pelos monocultivos de milho e de capim tifton e por quatro épocas de transplantio de capim tifton nas entrelinhas de semeadura do milho (SM), sendo: simultâneo, aos 15, 30 e 45 dias após a SM. Para o milho, avaliaram-se: biomassa de 100 grãos, número de fileiras de grãos por espiga, produtividade de grãos, altura da planta e inserção da primeira espiga. A biomassa seca do capim tifton foi estimada a partir de dois cortes, com intervalo de 20 dias entre a primeira e a segunda coleta. Para avaliar a eficiência dos consórcios em relação aos monocultivos, utilizou-se o índice de equivalência de área. Os resultados obtidos foram submetidos ao teste de Shapiro-Wilk ( $\mathrm{p} \leq 0,05)$, a fim de aferir a normalidade dos dados, seguido pela análise de variância. Foram ajustados modelos de regressão para as épocas de implantação do capim tifton nas entrelinhas do milho, quando houve efeito significativo pelo teste F, a $5 \%$ de probabilidade. Utilizou-se o teste de Dunnet $(\mathrm{p} \leq 0,05)$ para as comparações entre o milho consorciado com tifton e os monocultivos (testemunha). O milho não sofre interferência quando consorciado com capim tifton. Entretanto, o tifton apresenta menor acúmulo de biomassa seca quando consorciado com o milho. O melhor desempenho do consórcio verificou-se na implantação simultânea do milho com capim tifton.

Palavras-chave: Cynodon dactylon, integração Lavoura-Pecuária, Zea mays.

\section{ABSTRACT}

\section{Corn intercropped with tifton in south western Amazonia}

The objective of this work was to evaluate the performance of intercropped corn with tifton grass in South Western Amazonia. The experimental design was randomized blocks with six treatments and four replications. The treatments consisted of corn monocultures and tifton grass, and four transplantation periods of tifton between the corn sowing lines, as follows: simultaneously, at 15,30 and 45 days after sowing corn. For corn, these were evaluated: biomass of 100 grains, number of kernel rows per ear, grain yield, plant height and insertion of the first spike. The dry biomass of tifton grass was estimated from two cuts with an interval of 20 days between the first and second collections. To evaluate the performance of intercrops compared to monocultures, we used the area equivalence ratio. The results were submitted to the Shapiro-Wilk test ( $\mathrm{p} \leq 0.05$ ) in order to assess the normality of the data, followed by analysis of variance. Regression models were adjusted for the period of implantation of tifton grass between the corn sowing lines, when there was a significant effect by $\mathrm{F}$ test, at $5 \%$ probability. The Dunnet test was used $(\mathrm{p} \leq 0.05)$ for the comparisons between the corn intercropped with tifton and monocultures (control). Corn is not affected when intercropping with tifton grass. However, tifton has a lower accumulation of dry biomass when intercropped with corn. The best performance of the consortium was the simultaneous implantation of corn with tifton grass.

Key words: Cynodon dactylon, Crop-Livestock Integration, Zea may.

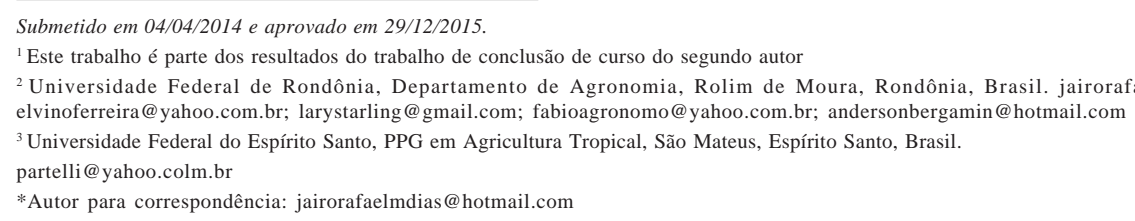




\section{INTRODUÇÃO}

A atividade pecuária na Amazônia brasileira consolidase sobre vastas áreas de pastagens, representando a maior forma de uso do solo, com 51 milhões de hectares, que corresponde a $70 \%$ da área desmatada nesse bioma. São pastagens que se encontram em diferentes estádios de degradação, caracterizando-se como uma atividade de baixa produtividade. Entretanto, entre 35 e $70 \%$ da pecuária bovina e da bubalina, respectivamente, do Brasil, encontram-se nessa região (Homma, 2010).

Neste cenário, o Estado de Rondônia destaca-se como detentor do segundo maior rebanho de bovinos da região norte do Brasil, com mais de 12,2 milhões de cabeças, ficando atrás apenas do Pará, com aproximadamente 18 milhões (Instituto Brasileiro de Geografia e Estatística, 2014). Em Rondônia, a pecuária é uma importante atividade para economia regional, com grande parte das pastagens formadas a partir da derrubada da floresta, sem nenhum planejamento e sem manejo da fertilidade do solo, tanto no estabelecimento quanto na manutenção dessas áreas forrageiras (Cerri et al., 2004).

Em Rondônia, o braquiarão (Brachiaria brizantha cv. Marandu) predomina como a principal espécie forrageira cultivada. Essa forrageira apresenta alta produtividade e adaptação às condições edafoclimáticas da região; no entanto, vem-se tornando cada vez mais vulnerável às pressões bióticas e abióticas, em função da extensa área cultivada, caracterizada pela monocultura e pela falta de manejo adequado (Noronha et al., 2010).

Dentre os principais fatores de vulnerabilidade que afetam as pastagens ao longo dos anos, destacam-se as alterações na estrutura do solo, provocadas pela alta taxa de lotação, pela erosão, pelo decréscimo da fertilidade do solo e, principalmente, pelo incremento da comunidade de plantas daninhas, em decorrência da incapacidade da gramínea forrageira de sustentar bons rendimentos em baixos níveis de fertilidade (Townsend et al., 2009). Desta forma, um dos grandes desafios é transformar essas pastagens degradadas em áreas produtivas e sustentáveis, utilizando-se técnicas avançadas de produção, que não agridam o ambiente e sejam menos onerosas.

Dentre essas técnicas, a integração entre lavoura e pecuária (ILP) caracteriza-se por ser uma prática cultural promissora para preservar a produtividade das pastagens na Amazônia, o que contribui efetivamente para a sustentabilidade da atividade pecuária e da redução do desmatamento na floresta amazônica, especialmente no Estado de Rondônia (Noronha et al., 2010). Nesse sistema, o efeito residual da fertilização, oriunda do cultivo de grãos, torna-se fundamental para o estabelecimento da forrageira, em sucessão, além do acúmulo de nitrogênio, fósforo e carbono orgânico no solo (Rezende et al., 2004).

Na ILP, as culturas produtoras de grãos são preferencialmente cultivadas como espécies agrícolas e as gramíneas do gênero braquiária são as mais difundidas como forrageiras. Entretanto, o capim tifton pode ser uma alternativa forrageira, dada a sua alta capacidade de promover a descompactação de solos degradados (Magalhães et al., 2009; Severiano et al., 2010), além do seu alto valor nutritivo, em comparação com o das gramíneas do gênero braquiária (Soares Filho et al., 2002).

A integração entre culturas tem sido uma das formas de aumento da produtividade e do lucro, por unidade de área, dos produtores rurais e das regiões tropicais, nas quais fatores climáticos, como temperatura e energia luminosa, não apresentam limitações. Fatores como os arranjos espaciais, as épocas de implantação e os cultivares são importantes, pois podem ser manipulados para aumentar a eficiência da prática de consórcios entre culturas (Negreiros et al., 2002). Este trabalho teve como objetivo avaliar o desempenho do consórcio de milho com o capim tifton na Amazônia sul ocidental.

\section{MATERIAL E MÉTODOS}

O experimento foi conduzido de dezembro de 2011 a março de 2012, no município de Rolim de Moura, RO (1149’09,3"S e $61^{\circ} 37^{\prime} 52,19$ "O, com altitude de $220 \mathrm{~m}$ ). Na região predomina o clima Tropical Chuvoso - Aw (Köppen), com temperatura e precipitação média anual de $25^{\circ} \mathrm{Ce} 2.000 \mathrm{~mm}$, respectivamente. O período chuvoso está compreendido entre os meses de outubro e novembro e abril e maio. O primeiro trimestre do ano apresenta o maior acúmulo de chuvas. O período mais quente fica compreendido entre os meses de agosto e outubro (Rondônia, 2010).

O solo é classificado como Latossolo Vermelho eutrófico (Empresa Brasileira de Pesquisa Agropecuária, 2006) e sua análise antes da implantação do experimento resultou nos seguintes valores: $\mathrm{pH}\left(\mathrm{H}_{2} 0\right)=5,78 ;$ M.O. $=2,22\left(\mathrm{dag} \mathrm{dm}^{-3}\right) ; \mathrm{P}$ $=22,09\left(\mathrm{mg} \mathrm{dm}^{-3}\right) ; \mathrm{K}=164,22\left(\mathrm{mg} \mathrm{dm}^{-3}\right) ; \mathrm{Ca}=3,59\left(\mathrm{cmol} \mathrm{dm}^{-}\right.$ 3); $\mathrm{Mg}=0,81\left(\mathrm{cmol} \mathrm{dm}_{\mathrm{c}}^{-3}\right) ; \mathrm{H}+\mathrm{Al}=2,21\left(\mathrm{cmol} \mathrm{dm}_{\mathrm{c}}^{-3}\right) ; \mathrm{Al}=0$ $\left(\mathrm{cmol}_{\mathrm{c}} \mathrm{dm}^{-3}\right)$; Argila $=204\left(\mathrm{~g} \mathrm{~kg}^{-1}\right)$. No preparo do solo, utilizou-se o método convencional, com a correção da acidez, a fim de elevar a saturação de bases a $80 \%$. Aárea foi anteriormente cultivada com Panicum maximum cv. Mombaça.

O delineamento experimental utilizado foi em blocos ao acaso, com seis tratamentos e quatro repetições. Os tratamentos foram constituídos por quatro épocas de implantação do capim tifton (Cynodon dactylon cv. Tifton 85), em consórcio com a cultura do milho (Zea mays cv. Al Bandeirante), sendo: simultâneo, 15, 30 e 45 dias após a semeadura do milho, além dos tratamentos dados pelos monocultivos 
de milho e de capim tifton. A parcela experimental tinha $20 \mathrm{~m}^{2}$, sendo compostas por cinco linhas espaçadas de $0,80 \mathrm{~m}$, tendo como área útil às três linhas centrais, desprezando-se 0,5 m de cada extremidade.

A semeadura do milho foi realizada no dia 21/12/2011, distribuindo-se cinco sementes por metro linear, o que representou uma população equivalente a 62.500 plantas $\mathrm{ha}^{-1}$. Na semeadura do milho foram aplicados $26,4 \mathrm{~kg} \mathrm{ha}^{-1} \mathrm{deN}, 73,8$ $\mathrm{kg} \mathrm{ha}^{-1}$ de $\mathrm{P}_{2} \mathrm{O}_{5}$ e 40,6 $\mathrm{kg} \mathrm{ha}^{-1}$ de $\mathrm{K}_{2} \mathrm{O}$, utilizando-se como fontes ureia, superfosfato triplo e cloreto de potássio, respectivamente. A adubação de cobertura foi realizada a lanço, aos 20 dias após a emergência das plantas, aplicando-se a dose de $35,2 \mathrm{~kg} \mathrm{ha}^{-1}$ de $\mathrm{N}$, na forma de ureia. As mudas de capim tifton, com 0,20 a 0,30 m de comprimento e três a quatro gemas, foram transplantadas nas entrelinhas do cultivo de milho, com espaçamento de $0,5 \mathrm{~m}$ entre estolões.

As plantas foram mantidas em condições ideais de sanidade, fazendo-se o controle de insetos-praga e doenças foliares. Para o controle de insetos-praga, em especial de lagarta do cartucho, utilizou-se uma aplicação de inseticida com os princípios ativos Imidacloprido $\left(100 \mathrm{~g} \mathrm{ha}^{-1}\right)$ e Betaciflutrina (12,5 $\left.\mathrm{g} \mathrm{ha}^{-1}\right)$, aos sete dias após a semeadura do milho. $\mathrm{O}$ controle de plantas daninhas foi realizado por meio de capina manual.

A colheita do milho e o corte inicial do capim tifton foram realizados no dia 30/03/2012. No milho, avaliaram-se biomassa de 100 grãos, número de fileiras de grãos por espiga, produtividade de grãos, altura da planta e inserção da primeira espiga. Os caracteres alturas da planta e inserção da primeira espiga (medindo-se a altura entre o nível do solo e a base da inserção da última folha e primeira espiga, respectivamente) foram determinados a partir de cinco plantas coletadas na área útil de cada parcela. Para determinação da biomassa de 100 grãos e do número de fileiras de grãos por espiga, foram coletadas dez espigas em cada parcela. As avaliações que envolveram pesagem de grãos foram corrigidas para $13 \%$ de umidade.

No capim tifton, a produção de biomassa seca (BS) foi estimada por meio de amostragem com quadro metálico com área conhecida $\left(1 \mathrm{~m}^{2}\right)$, em altura de $11 \mathrm{~cm}$ do solo, lançado ao acaso na área útil de cada parcela. Realizaram-se duas coletas com intervalo de 20 dias entre o primeiro e o segundo cortes. Para determinação da BS, as amostras da forragem foram secadas em estufa com circulação forçada de ar, sob temperatura de $65^{\circ} \mathrm{C}$, por 72 horas.

Para avaliar a eficiência dos consórcios em relação aos monocultivos, utilizou-se o índice de equivalência de área (IEA), conforme metodologia proposta por Soares (2000): $\mathrm{IEA}=\mathrm{IIC}_{\mathrm{M}}+\mathrm{IIC}_{\mathrm{T}}$, em que: índice individual da cultura (IIC) corresponde a razão entre desempenho produtivo da monocultura e do consórcio para o milho $\left(\mathrm{M}_{\mathrm{c}} \div \mathrm{M}_{\mathrm{m}}\right)$ e capim tifton $\left(\mathrm{T}_{\mathrm{c}} \div \mathrm{T}_{\mathrm{m}}\right)$, respectivamente. $\mathrm{O}_{\mathrm{c}} \mathrm{e} \mathrm{T}_{\mathrm{c}}$ correspondem às produtividades do milho e do capim tifton cultivados em consórcio, e, $\mathrm{M}_{\mathrm{m}}$ e $\mathrm{T}_{\mathrm{m}}$, às produtividades do milho e capim tifton em monocultivo, respectivamente.

Os resultados obtidos foram submetidos ao teste de Shapiro-Wilk ( $\leq \leq 0,05)$, a fim de aferir a normalidade dos dados, seguido pela análise de variância. Foram ajustados modelos de regressão para as épocas de implantação do capim tifton nas entrelinhas do milho, quando o efeito foi significativo pelo teste $\mathrm{F}$, até $5 \%$ de probabilidade. Utilizouse, também, o teste de Dunnett ( $\mathrm{p} \leq 0,05)$, para comparações entre médias de tratamentos com a respectiva testemunha, ou seja, os monocultivos. As análises foram realizadas com o programa computacional Assistat 7.6 (Silva \& Azevedo, 2002).

\section{RESULTADOS E DISCUSSÃO}

Todos os dados seguiram distribuição normal. O desempenho do milho não foi afetado pelo consórcio com capim tifton, independentemente do período de estabelecimento da forrageira (Tabela 1). A produtividade do milho obtida neste trabalho foi superior à média produzida, no Estado de Rondônia, na safra de 2012/2013 (2.187 kg ha'-1), sendo a única exceção a obtida no consórcio estabelecido com capim tifton aos 30 dias após a semeadura do milho (Companhia Nacional de Abastecimento, 2013).

De forma semelhante, Pariz et al. (2009), avaliando o consórcio simultâneo de milho com capim tanzânia (Panicum maximum cv. Tanzânia), em comparação com a monocultura do milho, também não observaram diferenças para características vegetativas (alturas de planta e de espiga) e de componentes de produção (biomassa de 100 grãos, número de fileiras de grãos por espiga e rendimento de espigas).

Com relação ao desempenho do capim tifton consorciado com milho, independentemente da época de corte, ocorreu diminuição progressiva da produção de biomassa seca da forrageira, conforme se prolongou o tempo para o transplantio em relação à semeadura do milho, obtendo-se mais biomassa quando o estabelecimento do consórcio foi simultâneo (Tabela 2).

Acredita-se que a luz, dentre os fatores de produção, é aquele que se destaca na competição entre plantas monocotiledôneas. Sendo assim, o menor crescimento do capim tifton, quando em consórcio com o milho, deve-se, principalmente, à morfologia, ao hábito de crescimento e à composição entre duas espécies cultivadas. Embora ambas possuam mecanismo de carboxilação do tipo $\mathrm{C}_{4}$, o milho possui hábito de crescimento ereto e maior porte, o que aumenta a sua capacidade de interceptação da luz em comparação com a do capim tifton, que foi sombreado rapidamente, por ser uma planta estolonífera, de menor porte e de crescimento rasteiro (Santos et al., 2006). 
O capim tifton em monocultivo apresentou maior acúmulo de biomassa seca que a do cultivo consorciado, independentemente do momento do corte e período de implantação da forrageira nas entrelinhas do cultivo de milho. A presença do milho em cultivo simultâneo com capim tifton diminuiu a produtividade da forrageira, independentemente da época de corte, chegando a inviabilizar o seu estabelecimento quando o consórcio foi implantado aos 45 dias após a semeadura do milho (Tabela 3). O menor desempenho do capim tifton quando em consórcio está associado à baixa tolerância da espécie forrageira ao sombreamento (Neres et al., 2012).

Comparando-se o desempenho produtivo do capim tifton entre as modalidades de consórcio no primeiro e segundo cortes, observaram-se comportamentos distintos. O primeiro, relativo à monocultura e ao consórcio simultâneo com milho, cujo acúmulo de biomassa seca (BS) da forrageira no segundo corte foi sempre inferior ao do primeiro corte, e o segundo, referente aos consórcios da forrageira estabelecida aos 15 e 30 dias após a semeadura do milho, os quais mostraram maiores incrementos de BS do capim tifton no segundo, em comparação com os do primeiro corte (Tabela 3). Provavelmente, os reflexos em reduções e em acréscimos da produção de BS da forrageira, entre o primeiro e o segundo cortes estão relacionados com a sua ontogenia e ao estímulo promovido pelo corte, mesmo para a condição de semeadura tardia (Pereira et al., 2012).

Os índices de equivalência de área dos consórcios sempre foram superiores a 1, indicando boa eficiência do uso da terra. Quanto ao índice individual da cultura (IIC) observaram-se sempre valores superiores a 1 para o milho, sendo exceção o cultivo da forrageira em consórcio estabelecido aos 30 dias após a semeadura do milho. Entretanto, para o capim tifton, o IIC sempre foi inferior a 0,75 . Neste caso, a produtividade do milho consorciado contribuiu para elevação do IEA, o que indica que, para se alcançar a produtividade atingida nas modalidades de consórcio, seria necessário o aumento da área dos monocultivos, com valores variando de 6 a $75 \%$ para o milho consorciado com Tifton 85, aos 45 dias após a semeadura do milho e simultâneo, respectivamente (Tabela 4).

Tabela 1: Altura de plantas (AP), altura de inserção de espiga (AIE), número de fileira de grãos por espiga (NFGE), biomassa de 100 grãos (B100grãos) e produtividade de milho (Prod.) em consórcio com capim Tifton 85, simultâneo, aos 15, 30 e 45 dias após a semeadura do milho

\begin{tabular}{lccccccc}
\hline Característica & MT-S & MS-15 & MT-30 & MT-45 & CV(\%) & Eq. Reg. & R $^{\mathbf{2}}$ \\
\hline AP (m) & 2,05 & 2,09 & 2,04 & 2,10 & 11,42 & $\widehat{y}=2,07$ & - \\
AIE (m) & 1,23 & 1,28 & 1,30 & 1,35 & 7,48 & $\widehat{y}=1,29$ & - \\
NFGE (unid.) & 13 & 14 & 14 & 15 & 5,89 & $\widehat{y}=14$ & - \\
B100grãos (g) & 22,3 & 21,8 & 23,6 & 23,5 & 7,25 & $\widehat{y}=22,8$ & - \\
Prod. (Kg ha ${ }^{-1}$ ) & 2.250 & 2.400 & 2.050 & 2.290 & 12 & $\hat{y}=2.247$ & - \\
\hline
\end{tabular}

MT-S: Milho consorciado com Tifton 85, simultâneo; MT-15: Milho consorciado com Tifton 85 aos 15 dias após semeadura do milho; MT-30: Milho consorciado com Tifton 85 aos 30 dias após semeadura do milho; MT-15: Milho consorciado com Tifton 85, aos 45 dias após semeadura do milho.

Tabela 2: Produção de biomassa seca, no primeiro e segundo cortes do capim Tifton 85 em consórcio simultâneo, aos 15,30 e 45 dias após a semeadura do milho

\begin{tabular}{lccc}
\hline Característica & $\mathbf{C V}(\boldsymbol{\%})$ & Equação de regressão & $\mathbf{R}^{2}$ \\
\hline Biomassa seca no primeiro corte $\left(\mathrm{Kg} \mathrm{ha}^{-1}\right)$ & 31,58 & $\widehat{y}=11,75-0,27 *^{\mathrm{x}}$ & 0,96 \\
Biomassa seca no segundo corte $\left(\mathrm{Kg} \mathrm{ha}^{-1}\right)$ & 20,25 & $\hat{y}=8,57-0,18 * \mathrm{x}$ & 0,99 \\
\hline
\end{tabular}

Tabela 3: Produtividade de biomassa seca de capim Tifton 85 no primeiro e segundo corte, cultivado em monocultivo, consorciado com milho simultaneamente e, aos 15, 30 e 45 dias após a semeadura do milho

\begin{tabular}{lcc}
\hline \multirow{2}{*}{ Sistema de cultivo } & Primeiro corte & Segundo corte \\
\cline { 2 - 3 } & \multicolumn{2}{c}{ (kg ha $\left.^{-\mathbf{1}}\right)$} \\
\hline Tifton 85 em monocultivo & 16.500 & 11.800 \\
Tifton 85 em consórcio simultâneo com milho & $11.750(-)$ & $8.570(-)$ \\
Tifton 85 em consórcio com milho aos 15 dias & $5.100(-)$ & $5.550(-)$ \\
Tifton 85 em consórcio com milho aos 30 dias & $2.900(-)$ & $3.550(-)$ \\
Tifton 85 em consórcio com milho aos 45 dias & $0(-)$ & $0(-)$ \\
\hline
\end{tabular}

Médias seguidas de $(-)$ e $(+)$ foram inferiores e superiores, respectivamente à testemunha (capim tifton 85 em monocultivo), pelo teste de Dunnett, a $5 \%$ de probabilidade. 
Tabela 4: Produtividades das culturas e Índices de equivalência de área (IEA) dos consórcios entre milho e capim Tifton 85

\begin{tabular}{|c|c|c|c|c|c|}
\hline \multirow{2}{*}{ Tratamentos } & \multicolumn{2}{|c|}{ Milho } & \multicolumn{2}{|c|}{ Tifton 85} & \multirow{2}{*}{ IEA } \\
\hline & $\left(\mathrm{kg} \mathrm{ha}^{-1}\right)$ & IIC & $\left(\mathrm{kg} \mathrm{ha}^{-1)}\right.$ & IIC & \\
\hline MT-S & 2.250 & 1,04 & 11.750 & 0,71 & 1,75 \\
\hline MT-15 & 2.400 & 1,11 & 5.100 & 0,31 & 1,42 \\
\hline MT-30 & 2.050 & 0,95 & 2.900 & 0,18 & 1,13 \\
\hline MT-45 & 2.290 & 1,06 & 0,00 & 0,00 & 1,06 \\
\hline Monocultivo & 2.160 & 1,00 & 16.500 & 1,00 & - \\
\hline
\end{tabular}

MT-S: Milho consorciado com Tifton 85, simultâneo; MT-15: Milho consorciado com Tifton 85 aos 15 dias após semeadura do milho; MT30: Milho consorciado com Tifton 85 aos 30 dias após semeadura do milho; MT-15: Milho consorciado com Tifton 85, aos 45 dias após semeadura do milho; IIC: índice individual da cultura.

\section{CONCLUSÕES}

O milho não sofre interferência do capim tifton, independentemente do período de consórcio.

Retardamento do plantio do capim tifton em relação ao semeio do milho acarreta em redução de sua produção de biomassa.

\section{REFERÊNCIAS}

Cerri CEP, Bermoux M, Chaplot V, Volkoff B, Victoria RL, Melillo JM, Paustian K \& Cerri CC (2004) Assessment of soil property spatial variation in an Amazon pasture: Basis for selecting an agronomic experimental area. Geoderma, 123:51-68.

Companhia Nacional de Abastecimento (2013) Acompanhamento da safra brasileira: Grãos, nono levantamento, junho de 2013. Brasília, CONAB. 29p.

Empresa Brasileira de Pesquisa Agropecuária (2006) Centro Nacional de Pesquisa de Solos. Sistema brasileiro de classificação de solos, janeiro de 2006. Rio de Janeiro, EMBRAPA. 306p.

Homma A (2010) Política agrícola ou ambiental para resolver os problemas na Amazônia. Revista de Política Agrícola, 19:99102 .

Instituto Brasileiro de Geografia e Estatística (2014) Pecuária 2012: bovinos - efetivo dos rebanhos. Disponível em: < $\underline{\text { http:// }}$ www.ibge.gov.br/estadosat>. Acessado em: 21 de março de 2014.

Magalhães EM, Oliveira GC, Severiano EC, Costa KAP \& Castro MB (2009) Recuperação estrutural e produção do capim-Tifton 85 em um Argissolo Vermelho-Amarelo compactado. Ciência Animal Brasileira, 10:68-76.

Neres MA, Castagnara DD, Silva FB, Oliveira PSR, Mesquita EE, Bernardi TC, Guarianti AJ \& Vogt ASL (2012) Características produtivas, estruturais e bromatológicas dos capins Tifton 85 e Piatã e do feijão-guandu cv. Super N, em cultivo singular ou em associação. Ciência Rural, 42:862-869.

Negreiros MZ, Bezerra Neto F, Porto VCN \& Santos RHS (2002) Cultivares de alface em sistemas solteiro e consorciado com cenoura em Mossoró. Horticultura Brasileira, 20:162-166.

Noronha NCN, Andrade CA, Limonge FC, Cerri CC, Cerri CEP, Piccolo MC \& Feigl BJ (2010) Recovery of degraded pasture in Rondônia: macronutrients and productivity of Brachiaria brizantha. Revista Brasileira de Ciência do Solo, 34:1711-1720.

Pariz CM, Andreotti M, Tarsitano MAA, Bergamaschine AF, Buzetti S \& Chioderoli A (2009) Desempenhos técnicos e econômicos da consorciação de milho com forrageiras dos gêneros Panicum e Brachiaria em sistema de integração lavoura pecuária. Pesquisa Agropecuária Tropical, 39:360-370.
Pereira OG, Robetta R, Ribeiro KG, Santos MER, Fonseca DM \& Cecon PR (2012) Crescimento do capim-tifton 85 sob doses de nitrogênio e alturas de corte. Revista Brasileira de Zootecnia, 41:30-35.

Rezende LA, Assis LC \& Nahas E (2004) Carbon, nitrogen and phosphorus mineralization in two soils amended with distillery yeast. Bioresource Technology, 94:159-167.

Rondônia - Secretaria de Estado do Desenvolvimento Ambiental (2010) Boletim climatógico de Rondônia, ano 2007. Porto Velho, SEDAM. 36p.

Santos MV, Ferreira FA, Freitas FCL, Santos LDT \& Fonseca DM (2006) Controle de Brachiaria brizantha com uso do glyphosate após o estabelecimento de Tifton 85 (Cynodon spp.). Planta Daninha, 24:813-819.

Severiano EC, Oliveira GC, Dias Junior MS, Costa KAP, Castro MB \& Magalhães EM (2010) Potencial de descompactação de um Argissolo promovido pelo capim-tifton 85. Revista Brasileira de Engenharia Agrícola e Ambiental, 14:39-45.

Silva FAS \& Azevedo CAV (2002) Versão do programa computacional Assistat para o sistema operacional Windows. Revista Brasileira de Produtos Agroindustriais, 4:71-78.

Soares DM, Peloso MJD, Kluthcouski J, Gandolfi LC \& Faria DJ (2000) Tecnologia para o sistema consórcio de milho verde com feijão no plantio de inverno. Santo Antônio de Goiás, Embrapa Arroz e Feijão. 51p. (Boletim de Pesquisa, 10).

Soares Filho CV, Rodrigues LRA \& Perril SHV (2002) Produção e valor nutritivo de dez gramíneas forrageiras na região noroeste do Estado de São Paulo. Acta Scientiarum, 24:1377-1384.

Viegas Neto AL, Heinz R, Gonçalves MC, Correia AMP, Mota LHS \& Araújo WD (2012) Milho pipoca consorciado com feijão em diferentes arranjos de plantas. Pesquisa Agropecuária Tropical, 42:28-33.

Townsend CR, Pereira RGA \& Costa NL (2009) Considerações sobre sistemas de integração lavoura-pecuária na Amazônia. Porto Velho, Embrapa Rondônia. 29p. (Documentos, 130). 